Visión Antataura

Vol.4, No.1: 104-116

Junio - Noviembre, 2020

Panamá

ISSN 2520-9892

\title{
Competencias digitales de los estudiantes de primer ingreso del Programa Anexo Universitario de Macaracas
}

\section{Digital competences of freshmen students of the University Annex of Macaracas}

\author{
Linely M. Vergara . $^{1}$
}

${ }^{1}$ Maestría en Informática Educativa; Profesora, Universidad de Panamá, Centro Regional Universitario de Los Santos, Facultad de Informática, Electrónica y Comunicación; $\underline{\text { linely.vergara@up.ac.pa; }}$ https://orcid.org/0000-0002-9609-2258

Resumen: Este artículo presenta los resultados de un estudio aplicado a estudiantes de primer ingreso del Programa Anexo Universitario de Macaracas, Centro Regional Universitario de Los Santos de la Universidad de Panamá. Su finalidad consiste en determinar las competencias digitales que poseen esos estudiantes. Los resultados indican que el $80 \%$ de los encuestados navegan entre 1 y 3 horas a la semana en internet; el $46 \%$ tiene acceso a la red en cualquier lugar, puesto que cuentan con paquetes de datos en sus teléfonos y el uso que le dan mayormente, es el de buscar información para hacer tareas universitarias. Los discentes se sienten más competentes en el uso del chat para comunicarse con otras personas y menos competentes en la creación de blogs o bitácoras. Son capaces de utilizar diferentes navegadores para acceder a internet, sin embargo, tienen dificultades para usar programas para difundir presentaciones interactivas en la red.

Palabras clave: competencias digitales, TIC, estudiantes universitarios, anexo universitario.

Abstract: The article presents the results of a study applied to freshmen students of the Macaracas University Annex Program, Los Santos University Regional Center of the University of Panama, in order to determine the student's digital competences. The results indicate that $80 \%$ of those surveyed surf between 1 and 3 hours a week on the Internet, $46 \%$ have access to the web anywhere since they have data packages in their phones. and the use they mostly give to the net is to look for information to do university tasks. They feel more proficient in texting to communicate with others and less proficient in creating blogs; they are able to use different browsers to access the Internet; however, they find it difficult to use software to broadcast interactive presentations on the web.

Key words: digital competences, ICT, university students, university annex.

\section{Introducción}

El Programa Anexo Universitario de Macaracas, Centro Regional Universitario de Los Santos fue fundado en el año 2011, como respuesta a la necesidad educativa de cursar estudios universitarios en su propia comunidad. A partir de ese año, los moradores 
macaraqueños y los de otros pueblos vecinos han podido tener acceso a la educación superior en la máxima casa de estudios del país: la Universidad de Panamá.

Actualmente, se ofrecen las carreras de Licenciatura en: Informática para la Gestión Educativa y Empresarial, Derecho y Ciencias Políticas e Inglés, las cuales cursan los discentes de áreas apartadas de los distritos de Macaracas, Los Santos y Tonosí de la provincia de Los Santos, otros que llegan del distrito de Los Pozos, provincia de Herrera. Cabe decir, que estos estudiantes, debido a la distancia, el trabajo y otras obligaciones familiares no habían podido continuar sus estudios universitarios de manera regular.

Schmidt (2006) define competencia como "un conjunto de conocimientos, habilidades, destrezas y actitudes aplicados en el desempeño exitoso de una ocupación o cargo, combinando dentro de un sistema integrado a los diferentes conocimientos, experiencias, habilidades mentales, actitudes, valores, motivos, aptitudes y capacidades que permiten desempeñar tareas y actividades laborales con éxito" p.1. En el caso que se estudia, la competencia se refiere a aquellas habilidades y destrezas aplicados al ámbito educativo, las cuales se espera sean adquiridas por los estudiantes universitarios en el transcurso de su carrera y que les ayudarán en el desempeño de su profesión.

La Recomendación del Parlamento Europeo y del Consejo sobre las competencias claves para el aprendizaje permanente (Diario Oficial de la Unión Europea, 30 de diciembre de 2006) establece como marco de referencia 8 competencias, entre las que destaca la competencia digital, como fundamental, para poder adaptarse al mundo cambiante en el que los seres humanos se encuentren. El dominio de herramientas tecnológicas, cada día se hace más importante como competencia esencial para los estudiantes universitarios. Es desde esa necesidad, de saber utilizar la tecnología como apoyo al proceso educativo, cuando surge el concepto de competencia digital.

Esteve y Gisbert (2012) definen la competencia digital como "una combinación de conocimientos, habilidades, destrezas y actitudes, para acceder, analizar, evaluar, reflexionar críticamente, crear y actuar en cuatro diferentes áreas o alfabetizaciones: tecnológica, informacional, multimedia y comunicativa" p.372. 
Por otro lado, Gutiérrez y Tyner (2012) indican que la competencia digital "consiste en disponer de habilidades para buscar, obtener, procesar y comunicar información, y para transformarla en conocimiento" p.37.

Con esas definiciones, es posible darse cuenta que la amplitud del concepto va mucho más allá de la dimensión tecnológica y que su aproximación puede darse desde diferentes puntos de vista, incluyendo los aspectos interpersonal y comunicativo, para la producción de nuevos conocimientos.

La competencia digital es un factor de éxito en el estudiante universitario de primer ingreso, puesto que le facilitará el desarrollo de otras competencias deseables y así las corrobora García-Ruiz (2006): la responsabilidad, autoconfianza, capacidad de resolución de problemas, habilidades comunicativas, razonamiento crítico, flexibilidad, trabajo en equipo, iniciativa, planificación, innovación/creatividad.

Un aspecto importante a tomar en consideración al momento de evaluar las competencias digitales de los estudiantes universitarios es el de la diferenciación entre los nativos y los inmigrantes digitales. Gértrudix, Durán, Gamonal, Gálvez y García (2010) definen a los nativos digitales como "personas que utilizan la información de forma rápida, en paralelo y multitarea, prefiriendo la red como fuente de información veraz." p.15. Y, los inmigrantes digitales, son las personas que por necesidad han tenido que formarse en el uso de la tecnología y adaptarse a su uso. Al Programa Anexo Universitario de Macaracas asisten estudiantes de un amplio rango de edad, por lo que el grupo etario es también, otro factor a valorar en el estudio de sus competencias digitales.

Como referencia a estudios previos, relacionados al tema que se desarrolla, se menciona en primer lugar el de Centeno y Cubo (2013), quienes establecen el grado de competencia digital que tienen los estudiantes universitarios y las actitudes que poseen hacia las TIC. Y el trabajo de Gisbert y Esteve (2016), quienes determinan el perfil del estudiante en la era digital y plantean que no todos los estudiantes llegan a la universidad con un nivel adecuado de competencias digitales para su desempeño óptimo.

Más recientemente, Vázquez, Marín, Maldonado y García (2017); Vázquez, Reyes, Colmenares y López (2017) y Conde, Trujillo y Castaño (2017) desarrollaron investigaciones 
sobre el desarrollo de las competencias digitales de estudiantes en universidades de España, Ecuador y Colombia, respectivamente, utilizando el cuestionario Competencias básicas digitales 2.0 de estudiantes universitarios COBADI 2013 (Zapata Ros, 2013).

El acceso a la tecnología en la campiña interiorana de Panamá es muchas veces difícil, lo cual obstaculiza el logro de las competencias en una gran parte de los estudiantes del Programa Anexo Universitario de Macaracas. Ellos son personas procedentes de áreas rurales e inmigrantes digitales que han tenido un escaso o nulo acceso a la tecnología. En tal sentido, se hace imperante determinar sus competencias digitales, ya que éstas podrían ser el factor que garantice el éxito en los programas de estudio que inician.

El objetivo de este estudio es establecer las competencias digitales de los estudiantes de primer ingreso del Programa Anexo Universitario de Macaracas, que les facilitan el éxito en sus estudios académicos iniciales.

\section{Metodología}

Se desarrolló un estudio descriptivo cuantitativo, para el que se utilizó como instrumento de recolección de datos, una encuesta que fue aplicada a los estudiantes de primer ingreso del Programa Anexo de Macaracas y que están matriculados en las carreras de licenciatura en Informática, Derecho y Ciencias Políticas e Inglés, con el objetivo de determinar sus competencias digitales al ingresar a la universidad.

La muestra de esta investigación corresponde a los 38 estudiantes que se encontraban en las aulas de clases universitarias, el día de la aplicación del instrumento: 12 de noviembre de 2019. Es necesario indicar, que el total de los discentes de primer ingreso, matriculados en el segundo semestre 2019, sumaban un total de 45 estudiantes, que correspondió a la población total.

El instrumento de investigación se diseñó con base en el Cuestionario Competencias básicas digitales 2.0 de estudiantes universitarios COBADI 2013. De acuerdo a Vázquez, Marín, Maldonado y García (2017) "este cuestionario fue desarrollado por los investigadores para obtener una descripción de las competencias básicas digitales entre alumnos universitarios y se aplicó para su validación previamente a muestras de alumnos 
de la Universidad de Sevilla en el año 2014-15, así como en muestras de Ecuador y Venezuela 2015-16. El cuestionario cuenta con 31 ítems divididos en tres bloques principales." p.354.

Para el desarrollo y adecuación del cuestionario, se tomó como referencia las etapas para el desarrollo de un instrumento sobre competencias TIC en alumnos universitarios de Llorente y Cabero (2010), quienes incluyen la revisión previa, determinación del tipo de instrumento, elaboración y revisión de los ítems y elaboración de la versión final.

La encuesta fue adaptada a la realidad del entorno en que se realizó el estudio, por lo que, se obviaron algunas preguntas del cuestionario original y otros ítems recibieron modificaciones menores. Los cambios implicaron adecuaciones de estilo en la redacción del español de España al español latinoamericano. También se redujo el total de ítems a evaluar (de 31 a 20), ya que algunas tecnologías mencionadas en el formato original están en desuso o han sido reemplazadas por otras. Se eliminó el tercer bloque, porque no se adecuaba al objetivo de esta investigación.

El cuestionario utilizado está estructurado en 4 secciones: la primera, incluye los datos generales; la segunda, solicita información sobre el consumo de tecnología y las dos últimas partes corresponden a las competencias digitales a evaluar, divididas en dos bloques:

- Bloque I: competencias en conocimiento y uso de las TIC en la comunicación social y el aprendizaje colaborativo.

- Bloque II: competencias de uso de las TIC para la búsqueda y el tratamiento de la información.

Cada uno de los bloques de competencias, consta de 10 ítems, los cuales representan las diversas herramientas digitales que los estudiantes universitarios deben saber usar. En cada ítem los estudiantes valoran el nivel de competencia que poseen, con base en una escala que va de 1 a 4, en la que el 1 representa muy poca competencia y el 4, mucha competencia. Se incluyó también la opción NS (no sabe) para cuando ellos no conocieran la herramienta del ítem. 


\section{Resultados y discusión}

\section{- Datos generales de los estudiantes}

La tabla 1 muestra que, del total de los estudiantes encuestados, el 76.3\% de ellos son mujeres y el $23.7 \%$, hombres. El hecho de que en el Anexo Universitario de Macaracas estudien más mujeres que hombres concuerda con los indicadores de la Universidad de Panamá, Dirección General de Planificación y Evaluación Universitaria (2019), que dicen que el $64.8 \%$ de los estudiantes son mujeres y el $35.2 \%$ son hombres.

En cuanto a la carrera universitaria que cursan los discentes, el $27.8 \%$ corresponde a Informática para la Gestión Educativa y Empresarial, el 33.3\% a Inglés y el 38.9\% a Derecho y Ciencias Políticas; lo que representa la homogeneidad de la muestra en cuanto a cantidad de participantes por carrera.

La edad promedio de los encuestados es de 30.5 años, mayor a los 20 y 21.11 años de los estudios de Vázquez, Marín, Maldonado y García (2017) y Conde, Trujillo y Castaño (2017), respectivamente. Esto demuestra que existe un gran número de estudiantes de edad madura (inmigrantes digitales) en las aulas de clases de este Anexo Universitario.

Tabla 1. Distribución de los participantes en la encuesta, por carrera y sexo

\begin{tabular}{l|c|c|c|c|c}
\multicolumn{1}{c|}{ Carrera } & Hombres & \% & Mujeres & & \% \\
\hline $\begin{array}{l}\text { Informática para la Gestión Educativa y } \\
\text { Empresarial }\end{array}$ & 1 & 10 & 9 & & 90 \\
\hline Derecho y Ciencias Políticas & 5 & 33 & 10 & & 67 \\
\hline Inglés & 4 & 31 & 9 & & 69 \\
\hline Total & $\mathbf{1 0}$ & $\mathbf{2 3 . 7}$ & $\mathbf{2 8}$ & & $\mathbf{7 6 . 3}$ \\
\hline
\end{tabular}

Fuente: elaborado con los datos de la encuesta aplicada.

\section{- Datos sobre consumo de tecnología}

Los resultados que se presentan en la figura 1 revelan que: el 65.8\% de los estudiantes cuenta con computadora, el $55.3 \%$ posee tableta, el $47.4 \%$ tiene acceso a Internet en sus casas y el $84.2 \%$ dispone de smartphone. Llama poderosamente la atención, que la mayoría de los participantes son usuarios de smartphones (32 de 38 estudiantes), lo cual podría ser 
aprovechado para el desarrollo de estrategias metodológicas que involucren aprendizaje móvil.

Figura 1. Consumo de tecnología por los estudiantes

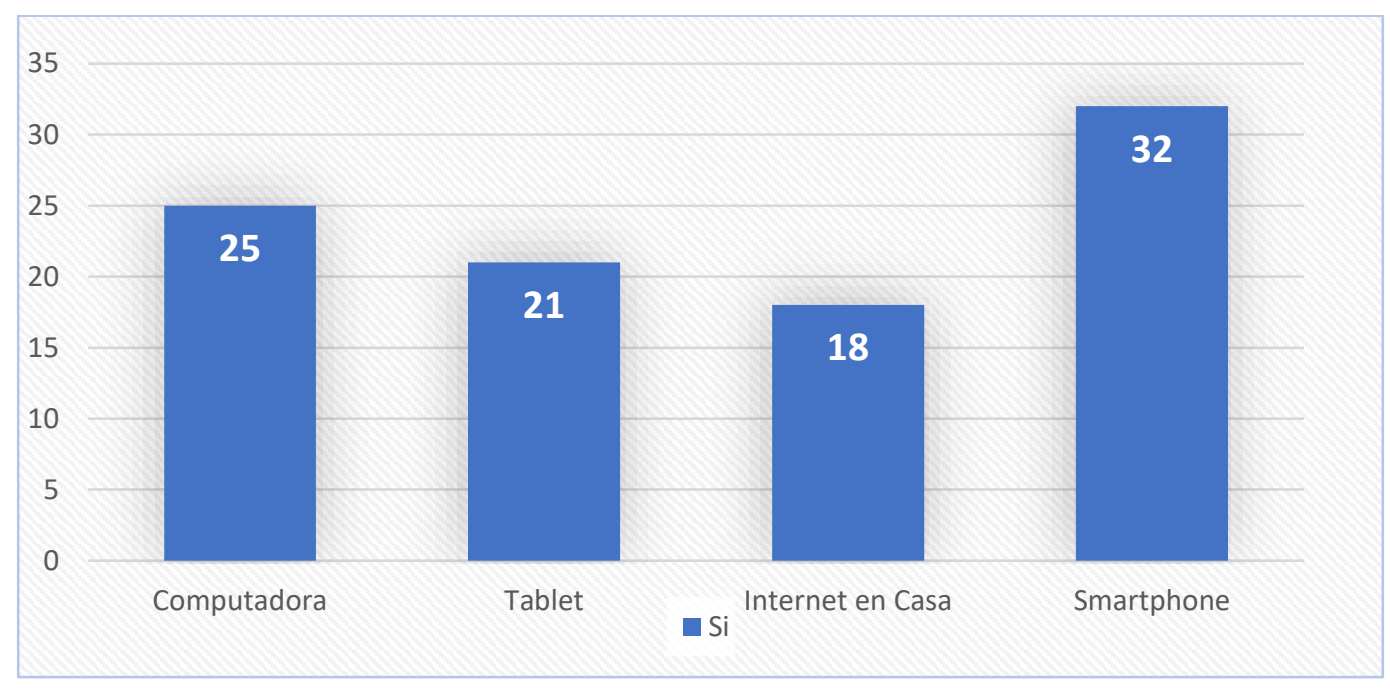

Fuente: elaborado con datos de la encuesta aplicada.

En cuanto al número de horas que dedican a navegar por la red de Internet, se descubre que el $80 \%$ la utiliza entre 1 y 3 horas en la semana; el 3\%, la usa entre 4 y 9 horas y el $17 \%$ la emplea más de 9 horas en la semana. Estos resultados demuestran que los estudiantes más jóvenes (18 y 19 años) son los que más horas semanales destinan al uso de Internet.

Con respecto al lugar donde mayormente se conectan a Internet, el $46 \%$ indica que lo hace desde cualquier lugar, puesto que cuentan con Internet en sus teléfonos. Seguido en orden de frecuencia, el $24 \%$ se conecta en sus casas, el $21 \%$ en la universidad y el $3 \%$ lo hace en casa de amistades, en un cibercafé u otros sitios. En este sentido, se determina que menos de la mitad de los estudiantes indagados (46\%) tiene acceso a Internet de forma permanente a través de sus dispositivos.

En cuanto a los usos de Internet, la figura 2 muestra que el $94.7 \%$ de los estudiantes (36) la utiliza para buscar información y realizar tareas universitarias; el $89.5 \%$ la emplea para informarse acerca de temas que le interesan; el $84.2 \%$ la utiliza para trabajar en grupo con compañeros de clase y hablar con amigos a través de redes sociales. En menor medida 
utilizan internet para escuchar o bajar música (73.7\% y 63.1\%, respectivamente), publicar fotografías o videos (57.9\%), ver programas de televisión (50\%), buscar amigos nuevos (39.5\%) o jugar online (10.5\%). Los bajos porcentajes de uso de internet en aspectos relacionados con entretenimiento están ligados al hecho de que, gran parte de los encuestados son inmigrantes digitales.

Figura 2. Usos de Internet de los estudiantes



Fuente: elaborado con datos de la encuesta aplicada.

- Bloque I: Competencias en el conocimiento y el uso de las TIC en la comunicación social y aprendizaje colaborativo.

Tomando como base los resultados de los aspectos donde los encuestados se sienten muy competentes ( 4 en la escala previamente establecida), la figura 3 evidencia que: el 18.4\% utiliza plataformas educativas; el 26,3\% usa las Wikis; el 5.3\% diseña blogs; el 7.9\% se siente competente para participar en blogs; el 21\% participa apropiadamente en foros; el $31.6 \%$ es capaz de desenvolverse en redes profesionales; el $44.7 \%$ puede comunicarse a través de redes sociales; el 39.5\% usa la mensajería instantánea para comunicarse; el 60.5\% utiliza el chat para relacionarse con otras personas y el $36.8 \%$ se comunica con otras 
personas mediante el correo electrónico. Por un lado, es preciso indicar que los resultados demuestran que las competencias digitales en las que los estudiantes presentan mayores dificultades son las que tienen que ver con la creación y el uso de blogs. Por otro lado, se destaca el hecho de que la mayoría (60.5\%) es competente en el uso del chat. Estos coinciden con los resultados obtenidos por Vázquez, Marín, Maldonado y García (2017) cuando enfatizan en la capacidad de los estudiantes, de comunicarse a través de diferentes medios electrónicos.

Figura 3. Competencias en el conocimiento y en el uso de las TIC en la comunicación social y el aprendizaje colaborativo

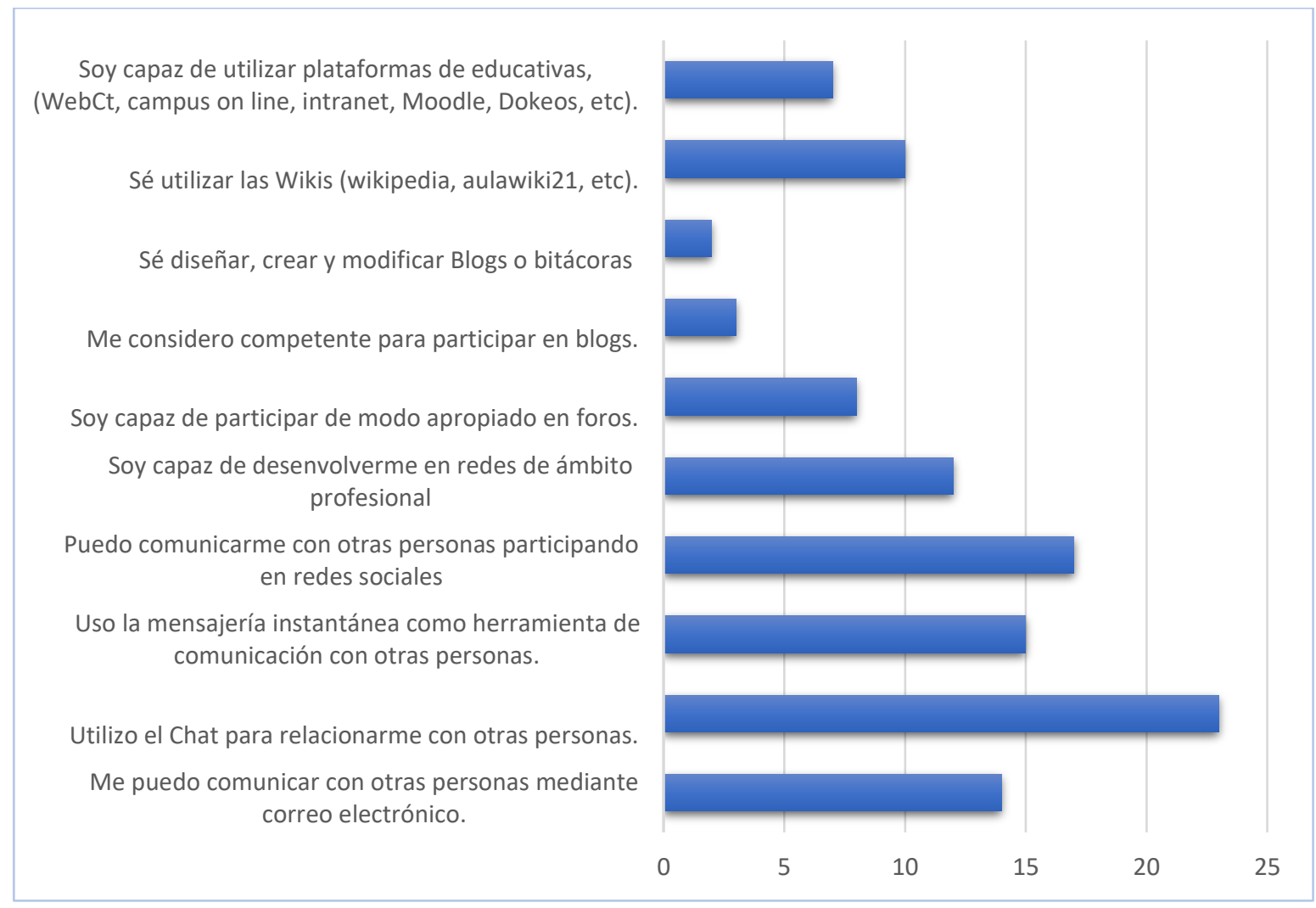

Fuente: elaborado con datos de la encuesta aplicada.

\section{- Bloque II: Competencias de uso de las TIC para la búsqueda y tratamiento de la información}

En cuanto al uso de las TIC para la búsqueda y tratamiento de la información, los resultados de la figura 4 muestran grandes deficiencias en este tipo de competencias, 
indicando los mayores valores del $55.6 \%$ en navegar por internet utilizando diferentes navegadores, lo cual concuerda con Vázquez, Reyes, Colmenares y López (2017), cuando determinan que la navegación por internet es el aspecto que más se destaca en la búsqueda y tratamiento de la información. Los resultados salieron muy bajos en el uso de programas para presentaciones interactivas como Prezi o Slideshare y en trabajar imágenes con herramientas de software social ( 7.9 y $10.5 \%$ respectivamente). Resalta también el hecho de que los estudiantes no son capaces de analizar y sintetizar información en mapas conceptuales utilizando alguna aplicación tecnológica, en el que solo se obtuvo un 13\%.

Figura 4. Competencias de uso de las TIC para la búsqueda y tratamiento de la información



Fuente: elaborado con datos de la encuesta aplicada.

\section{Conclusiones}

- Los resultados obtenidos con la aplicación del instrumento de investigación (encuesta) indican que la brecha digital entre la urbe y la campiña interiorana se mantiene, porque 
la mayoría de los estudiantes del Programa Anexo Universitario de Macaracas tiene acceso limitado a Internet y a dispositivos tecnológicos.

- A pesar de la variación en la franja etaria en investigaciones previas, los resultados de este estudio sobre el desarrollo de competencias son similares, considerando que existe en éste, un número representativo de inmigrantes digitales.

- El aprendizaje móvil es un nicho de oportunidad que puede ser implementado y explotado como complemento a la modalidad educativa presencial, considerando que, aunque los estudiantes no tienen acceso a datos permanentemente, la mayoría (84.2\%) cuenta con dispositivos móviles.

- El hecho de que los estudiantes demuestran destrezas en el uso de herramientas de comunicación a través de la red como: el chat, redes sociales y correo electrónico puede ser aprovechado para desarrollar un mayor flujo de comunicación didáctica entre el docente y los estudiantes, fuera del aula de clases.

- Los estudiantes utilizan la red principalmente, para realizar sus trabajos universitarios y navegar por internet para buscar información; sin embargo, no son capaces de utilizar algunas herramientas de la web como es el caso de los blogs y las herramientas de presentación.

\section{Referencias bibliográficas}

Centeno, G., y Cubo, S. (2013). Evaluación de la competencia digital y las actitudes hacia las TIC del alumnado universitario. Revista De Investigación Educativa, 31(2), 536. Recuperado de: https://doi.org/10.6018/rie.31.2.169271

Conde E., Trujillo J., Castaño H. (2017). Descifrando el currículum a través de las TIC. Una visión interactiva sobre las competencias digitales de los estudiantes de Ciencias del Deporte y de la Actividad Física. Revista de humanidades UNED, 31. Recuperado de: https://dialnet.unirioja.es/servlet/articulo?codigo $=6004965$

Diario Oficial de la Unión Europea (30 de diciembre de 2006). Recomendación del Parlamento Europeo y del Consejo, de 18 de diciembre de 2006, sobre las competencias clave para el aprendizaje permanente, L 394/10. 
Dirección General de Planificación y Evaluación Universitaria (2019). Boletín de Estadística de la Universidad de Panamá, Primer Semestre del Año Académico 2019, Edición 94.

Esteve, F., y Gisbert, M. (2012). La competencia digital de los estudiantes universitarios: Definición conceptual y análisis de cinco instrumentos para su evaluación. Recuperado de https://www.researchgate.net/profile/Francesc Esteve/publication/233721481 La competencia digital de los estudiantes universitarios Definicion conceptual y a $\underline{\text { nalisis de cinco instrumentos para su evaluacion/links/0912f50b33d967d777000 }}$ 000.pdf

García-Ruiz, R. (2006) Las competencias de los alumnos universitarios. Revista interuniversitaria de formación del profesorado. ISSN: 0213-8646, 20 (3), 253-270. Recuperado de: https://www.redalyc.org/articulo.oa?id=274/27411311013

Gértrudix, F., Durán, J.F., Gamonal, R., Gálvez de la Cuesta, M. y García, F. (2010). Una taxonomía del término "nativo digital": nuevas formas de relación y de comunicación. Congreso Euro-Iberoamericano de Alfabetización Mediática y Culturas Digitales Sevilla: Universidad de Sevilla. Recuperado de: https://idus.us.es/handle/11441/57014

Gisbert, M., y Esteve, F. (2016). Digital Learners: la competencia digital de los estudiantes universitarios. La cuestión universitaria, 7, 48-59. Recuperado de: http://polired.upm.es/index.php/lacuestionuniversitaria/article/view/3359

Gutiérrez, A. y Tyner, K. (2012). Educación para los medios, alfabetización mediática y competencia digital. Comunicar, XIX, 38, 31-39. ISSN: 1134-3478. Recuperado de: https://www.redalyc.org/articulo.oa?id=15823083005

Llorente, M. y Cabero J. (2010). Desarrollo de un instrumento sobre Competencias TIC en alumnos Universitarios. Alfabetización mediática y culturas digitales, ISBN 978-84693-2361-8. Recuperado de: https://idus.us.es/handle/11441/56142

Schmidt, S. (2006). Competencias, habilidades cognitivas, destrezas prácticas y actitudes definiciones $y$ desarrollo. Recuperado de: https://www.academia.edu/download/54821960/definicion-comphabdestrezas.pdf 
Vázquez, E., Marín, V., Maldonado, G. y García, E. (2017). La competencia digital del alumnado universitario de ciencias sociales desde una perspectiva de género. Prisma Social, 19, Recuperado de: https://www.redalyc.org/articulo.oa?id=353754089013

Vázquez, E., Reyes M., Colmenares, L., y López, E. (2017). Competencia digital del alumnado de la Universidad Católica de Santiago de Guayaquil. Opción, 33 (83), Recuperado de: http://produccioncientificaluz.org/index.php/opcion/article/viewFile/23115/23156

Zapata, M. (2013). Competencias Básicas Digitales 2.0 de los estudiantes universitarios COBADI 2013 (marca registrada: 2970648). Recuperado de: http://www.scoop.it/t/competencia-digital-docente 